\title{
ESR Studies of Fast Electron Irradiated Ferroelectric Poly(Vinylidene Fluoride)
}

\author{
J. Goslar, B. Hilczer* And H. Smogór \\ Institute of Molecular Physics, Polish Academy of Sciences \\ Smoluchowskiego 17, 60-179 Poznań, Poland
}

\begin{abstract}
Radiation-induced functionalization of ferroelectric poly(vinylidene fluoride) was studied by ESR spectroscopy. The samples were irradiated in the high vacuum of a Van de Graaff accelerator with $1.0 \mathrm{MeV}$ and $1.5 \mathrm{MeV}$ electrons at room temperature and the decay of free radicals was studied after transferring the samples into the air. The samples exhibit a multicomponent ESR spectrum that can be decomposed into: a large asymmetric signal in the centre related to peroxy radicals, a quintet with hyperfine splitting $A_{\mathrm{F}}=4.3 \mathrm{mT}$ centred at $g=2.004$, assigned to the in-chain radical $\left(-\mathrm{CF}_{2}-\mathrm{C}^{\bullet} \mathrm{H}-\mathrm{CF}_{2}-\right)$, and a triplet due to an end-chain $\left(-\mathrm{C}^{\bullet} \mathrm{H}_{2}\right)$ radical with $A_{\mathrm{H}}=1.6 \mathrm{mT}$ and $g=2.009$.
\end{abstract}

PACS numbers: 61.80.Fe, 61.82.Pv, 76.30.Rn, 77.84.Jd, 78.30.Jw

\section{Introduction}

Ferroelectric behavior has been found in $\left(-\mathrm{CH}_{2}-\mathrm{CF}_{2}-\right)_{n}$ polymer with planar-zigzag all-trans conformation packed in a parallel manner and the dipole moment perpendicular to the chain axis $[1,2]$. The material, denoted as PVDF, is of great interest since its properties can be easily tailored to various application requirements by fast electron irradiation. Radiation-induced functionalization of ferroelectric properties of PVDF consists in a downward shift of the ferroelectric-paraelectric phase transition, broadening and decrease in the Curie point anomaly, and a considerable increase in the dielectric dispersion [3]. Here we would like to report the results of ESR studies of the processes responsible for radiation-induced modification of the properties of ferroelectric PVDF.

*corresponding author; e-mail: bhilczer@ifmpan.poznan.pl 
Stable radicals in PVDF induced by ionizing radiation have been previously studied by optical, EPR, and ENDOR spectroscopy [4-6]. Irradiation was found to break the $\mathrm{C}-\mathrm{H}$ and $\mathrm{C}-\mathrm{F}$ bonds, leading to formation of in-chain radicals, whereas the scission of $\mathrm{C}-\mathrm{C}$ bonds resulted in producing of end-chain radicals $[5,7]$. Some of the radicals become oxygenated in the air and the ESR spectra of PVDF have been described as composed of one or more types of radicals such as $\left(-\mathrm{CF}_{2}-\mathrm{C}^{\bullet} \mathrm{H}-\mathrm{CF}_{2}-\right),-\mathrm{C}^{\bullet} \mathrm{H}_{2},-\mathrm{C}^{\bullet} \mathrm{F}_{2}$ as well as of peroxy radicals and long life polyenyl $\left(-\mathrm{CH}_{2}-(\mathrm{CF}=\mathrm{CH})_{n}-\mathrm{C}^{\bullet} \mathrm{F}-\mathrm{CH}_{2}-\right)$ radicals [8]. The polyenyl radicals, with the unpaired electron delocalized over few $\mathrm{C}=\mathrm{C}$ bonds can be formed due to the desorption of HF [7].

The ESR measurements of PVDF irradiated with fast electrons in high vacuum of a Van de Graaff accelerator allowed us to determine the type and concentration of free radicals trapped in the polymer as well as the radical decay.

\section{Experimental}

Ferroelectric radially-oriented polymer samples were obtained from PVDF powder (Nitrogeneous Concern, Tarnów, Poland) by hot-pressing at $p=600 \mathrm{MPa}$ and $T=450 \mathrm{~K}$. The samples were irradiated in the Van de Graaff accelerator with electrons of energy $E^{*}=1.0 \mathrm{MeV}$ and $1.5 \mathrm{MeV}$ and doses $D^{*}=0.75-1.75 \mathrm{MGy}$ at $T^{*}=300 \mathrm{~K}$. The current density of the electrons amounted to $0.1 \mu \mathrm{A} / \mathrm{cm}^{2}$. The samples were transferred from the high vacuum of the accelerator into the air and time-evolution of the ESR spectra was studied at room temperature.

The spectra were recorded on a Radiopan SE/X-2547 spectrometer operating at X-band microwave frequency with a cylindrical $\mathrm{TE}_{011}$ cavity and $100 \mathrm{kHz}$ magnetic modulation. The $g$-factors describing the ESR line positions in the magnetic field were calculated as $g=71.4484 \nu / B$, where $\nu$ denotes the resonance frequency (in $\mathrm{GHz}$ ) measured by HP $5340 \mathrm{~A}$ frequency counter, and $B$ is the magnetic field (in $\mathrm{mT}$ ) determined from field markers generated by the NMR magnetometer. Free radical concentration was determined by EPR with respect to the Ultramarine Blue Standard having $6.3 \times 10^{15}$ spins of the $\mathrm{S}_{3}^{-}$radicals and the peak-to-peak line width $\Delta B_{\mathrm{pp}}=1.9 \mathrm{mT}$. EPR spectra were simulated using Bruker SIMFONIA routine.

After the decay of free radicals we controlled the concentration of isolated and conjugated $\mathrm{C}=\mathrm{C}$ bonds in the samples by IR spectroscopy on Perkin-Elmer FT-IR 1725X spectrometer.

\section{Results and discussion}

Fast electron irradiation of PVDF in the high vacuum of the Van de Graaff accelerator leads to a scission of $\mathrm{C}-\mathrm{H}, \mathrm{C}-\mathrm{F}$, and $\mathrm{C}-\mathrm{C}$ bonds and creation of $\left(-\mathrm{CF}_{2}-\mathrm{C}^{\bullet} \mathrm{H}-\mathrm{CF}_{2}-\right)$ and $\left(-\mathrm{CH}_{2}-\mathrm{C}^{\bullet} \mathrm{F}-\mathrm{CH}_{2}-\right)$ in-chain radicals as well as two 
kinds of end-chain radicals: $\left(-\mathrm{CF}_{2}-\mathrm{C}^{\bullet} \mathrm{H}_{2}\right)$ and $\left(-\mathrm{CH}_{2}-\mathrm{C}^{\bullet} \mathrm{F}_{2}\right)$. On transferring the samples from the high vacuum into the air, alkoxy or alkyl peroxy radicals appear [9].

Figure 1 shows changes in the ESR spectra of PVDF after irradiation with various doses of $1.5 \mathrm{MeV}$ electrons at $300 \mathrm{~K}$. It can be seen that the spectra of irradiated PVDF are multicomponent. An analysis of a typical ESR spectrum of fast electron irradiated PVDF is shown in Fig. 2 together with simulated spectra of three radical components. In the centre of the spectrum a large asymmetric signal corresponding to a peroxy radical $\left(\mathrm{RO}_{2}^{\bullet}\right)$ appears (dotted line). This asymmetric component has a characteristic line shape arising from the axially symmetric $g$-tensor. Its principal values at room temperature are: $g_{\|}=g_{z}=2.0327$ and $g_{\perp}=g_{x}=g_{y}=2.009$. The axially symmetric spectrum indicates that $g_{x}$ and $g_{y}$ are averaged by rapid motions because the $g$-tensor of the peroxy radicals trapped in a phase with a restricted mobility is of the rhombic symmetry, as observed in the crystalline phase of irradiated polypropylene [10]. Thus, after transferring the sample into the air the alkyl radicals undergo oxidative reaction and the alkyl-peroxy radicals are formed in the main chain positions as $\left(-\mathrm{CH}_{2}-\mathrm{CF}(\mathrm{OO})^{\bullet}-\mathrm{CH}_{2}-\right)$.

The five-line spectrum (thin solid line) with hyperfine splitting of $4.3 \mathrm{mT}$ centred at $g_{\text {iso }}=2.004$ can be attributed to the in-chain alkyl radical $\left(-\mathrm{CF}_{2}-\mathrm{C}^{\bullet} \mathrm{H}-\right.$ $\mathrm{CF}_{2}-$ ) created in a direct interaction of electrons with the polymer. The computer simulations showed that the hyperfine splittings of this radical necessary to repro-

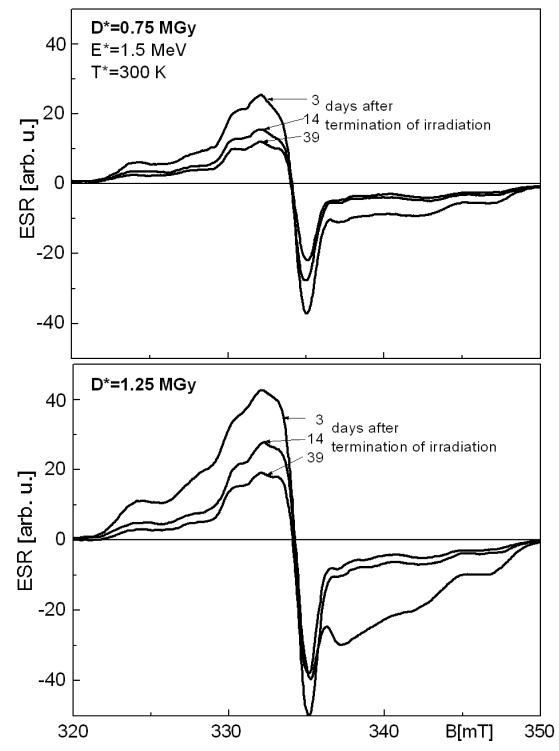

Fig. 1. Room temperature ESR spectra of PVDF irradiated with various doses $D^{*}$ of $1.5 \mathrm{MeV}$ electrons at $T^{*}=300 \mathrm{~K}$, recorded at different times after termination of irradiation. 


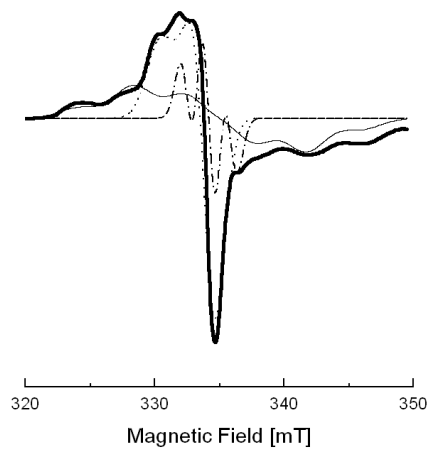

Fig. 2. Analysis of a typical ESR spectrum of fast electron irradiated PVDF $\left(E^{*}=\right.$ $1 \mathrm{MeV}, D^{*}=1.25 \mathrm{MGy}, T^{*}=300 \mathrm{~K}, 3$ days after termination of irradiation).

duce a quintet pattern should be: $A_{\mathrm{F}}=4.3 \mathrm{mT}, A_{\mathrm{H}}=2.3 \mathrm{mT}$, and $g_{\text {iso }}=2.004$. Not resolved superhyperfine splitting $A_{\mathrm{H}}$ determines the Gaussian line width of the individual line of the quintet as equal to $3.3 \mathrm{mT}$.

The third component of the experimental signal is a triplet-line spectrum (dotted-dashed line) with a hyperfine splitting $A_{\mathrm{H}}$ of $1.6 \mathrm{mT}$ and $g=2.009$ and is due to the $\left(-\mathrm{C}^{\bullet} \mathrm{H}_{2}\right)$ end-chain radical.

The ESR parameters of identified radicals are collected in Table and are consistent with those of the most commonly occurring radicals in PVDF [11].

TABLE

ESR spectral data for component radicals.

\begin{tabular}{c|c|c|c}
\hline \hline Radical & $-\mathrm{CH}_{2}-\mathrm{CF}(\mathrm{OO})^{\bullet}-\mathrm{CH}_{2}-$ & $-\mathrm{CF}_{2}-\mathrm{C}^{\bullet} \mathrm{H}-\mathrm{CF}_{2}$ & $-\mathrm{C}^{\bullet} \mathrm{H}_{2}$ \\
\hline$g$ & $g_{\|}=2.0327, g_{\perp}=2.009$ & $g_{\text {iso }}=2.004$ & $g_{\text {iso }}=2.009$ \\
$\Delta B_{\mathrm{pp}}[\mathrm{mT}]$ & $\Delta B_{\mathrm{pp}}^{\|}=2.0, \Delta B_{\mathrm{pp}}^{\perp}=1.8$ & $\Delta B_{\mathrm{pp}}=3.3$ & $\Delta B_{\mathrm{pp}}=1.2$ \\
$A[\mathrm{mT}]$ & - & $A_{\mathrm{F}}=4.3, A_{\mathrm{H}}=2.3$ & $A_{\mathrm{H}}=1.6$
\end{tabular}

Though the integral intensity of the ESR spectra of irradiated PVDF decays, the signals originating from both primary and oxygenated radicals are observed after $\approx 2$ months of storage at room temperature. Figure 3 shows the room temperature decay of the radicals in PVDF samples irradiated with various doses of $1.0 \mathrm{MeV}$ and $1.5 \mathrm{MeV}$ electrons. The total concentration of radicals trapped in irradiated polymer varies, depending on the energy of the irradiation and two decay processes can be distinguished. The fast decay may be related to the recombination reactions of alkyl radicals, whereas the decay rate of alkyl-peroxy radicals is slower. The decay of free radicals is accompanied by a desorption of $\mathrm{HF}$ and is responsible for the formation of isolated and conjugated $\mathrm{C}=\mathrm{C}$ bonds in irradiated PVDF. The double carbon-carbon bonds were revealed by us by IR spectroscopy in PVDF $\approx 2$ months after termination of electron irradiation. A band at $1754 \mathrm{~cm}^{-1}$ was 


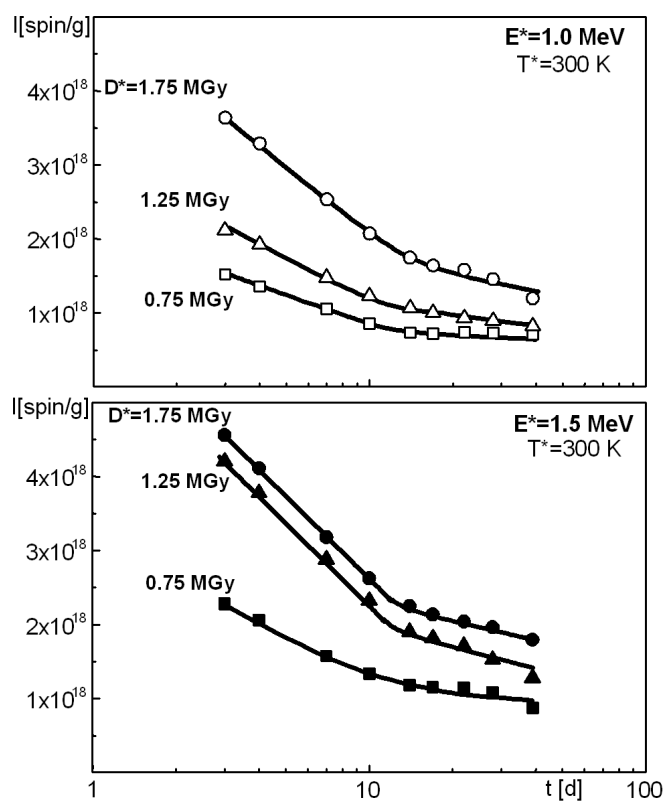

Fig. 3. Room temperature decay of the free radical density in PVDF irradiated at $T^{*}=300 \mathrm{~K}$ with various doses $D^{*}$ of $1.0 \mathrm{MeV}$ and $1.5 \mathrm{MeV}$ electrons.

attributed to vibrations of isolated $\mathrm{C}=\mathrm{C}$ bonds, a strong band at $1713 \mathrm{~cm}^{-1}$ appears from vibrations of $\mathrm{C}=\mathrm{C}$ pairs, and weaker bands observed at $1680 \mathrm{~cm}^{-1}$, $1652 \mathrm{~cm}^{-1}$, and $1616 \mathrm{~cm}^{-1}$ are related to three, four and five conjugated $\mathrm{C}=\mathrm{C}$ bonds, respectively [12]. Thus after the free radical decay in fast electron irradiated PVDF one can expect also the polyenyl radicals with free electrons delocalized over several $\mathrm{C}=\mathrm{C}$ bonds. A weak ESR signal with $g=2.0175$ and peak-peak line width of $\approx 1.4 \mathrm{mT}$, attributed to the polyenyl radicals, was reported by us for vinylidene-trifluoroethylene copolymers irradiated with $1.0 \mathrm{MeV}$ electrons at $T^{*}=420 \mathrm{~K}[3]$.

\section{Acknowledgments}

The paper was supported by a grant 2 PO3B 12421 from the State Committee for Scientific Research.

\section{References}

[1] T. Furukawa, M. Date, E. Fukada, J. Appl. Phys. 51, 1135 (1980).

[2] K. Tashiro, in: Ferroelectric Polymers - Chemistry, Physics and Applications, Ed. H.S. Nalwa, Marcel Dekker, New York 1995, p. 62.

[3] B. Hilczer, H. Smogór, J. Goslar, J. Mater. Sci., accepted for publication. 
[4] F. Macchi, B. Daudin, A. Ermolieff, S. Marthon, Radiat. Eff. Defects Solids 118, 117 (1991).

[5] E. Adem, G. Burillo, E. Munoz, J. Rickards, L. Cota, M. Avalos-Borja, Pol. Deg. Stab. 81, 75 (2003).

[6] J.N. Helbert, B.E. Wagner, E.H. Poindexter, L. Kevan, J. Polym. Sci. 13, 825 (1975).

[7] J.S. Forsythe, D.J.T. Hill, Prog. Polymer Sci. 25, 5668 (2000).

[8] Y. Komaki, N. Ishikawa, N. Morishita, S. Takamura, Radiat. Meas. 26, 123 (1996).

[9] B. Ranby, J.F. Rabek, ESR Spectroscopy in Polymer Research, Springer Verlag, Berlin 1977, p. 254.

[10] P. Silva, C. Albano, R. Perera, J. Gonzalez, M. Ichazo, Nucl. Instrum. Methods Phys. Res. B 226, 320 (2004).

[11] D. Suryanarayana, L. Kevan, J. Am. Chem. Soc. 104, 6251 (1982).

[12] B. Schrader, Infrared and Raman Spectroscopy. Methods and Applications, VCH Publishers Inc., New York 1995, p. 190. 